\title{
The Difficulties and Countermeasures of Rural E-commerce Poverty Alleviation in Ethnic Regions in China
}

\author{
Rangjia Cai ${ }^{1, a}$, Haiying $\mathrm{Ma}^{2, \mathrm{~b}^{*}}$ and Yongteng $\mathrm{Ma}^{3, \mathrm{c}}$ \\ ${ }^{1,2,3}$ School of Economics, Northwest Minzu University \& Provincial Key Laboratory of E-commerce of \\ Ethnic Information, Northwest Minzu University, Lanzhou (730124), P.R.China

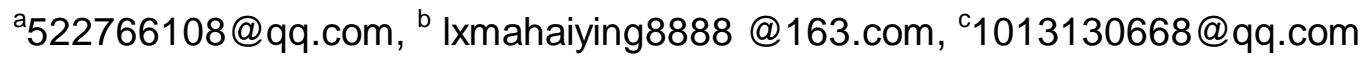

\begin{abstract}
Keywords: Ethnic regions; E-commerce poverty alleviation; Last kilometer; Agricultural special product
\end{abstract}

\begin{abstract}
Under the Internet+ era, the accurate poverty alleviation of E-commerce has opened up a new path for the country to help the poor. E-commerce-based poverty alleviation in rural areas in ethnic areas can help make full use of modern Internet technologies, organically link ethnic minority agricultural products and related industries with E-commerce and logistics systems, increase the income of poor ethnic minority farmers, and ensure that ethnic minorities and ethnic regions achieve full-scale well-off on schedule. Building a rural E-commerce logistics and public service system covering remote ethnic areas, building rural E-commerce pro-poor professionals, implementing rural E-commerce industry chain extension and brand promotion strategies, and optimizing rural E-commerce poverty alleviation policy guidance, and continue to promote rural areas in ethnic areas.
\end{abstract}

\section{Introduction}

According to statistics from the National Bureau of Statistics, there are still 67 million poor people in rural areas in China, accounting for about $7.2 \%$ of rural residents. Poverty problems need to be solved urgently. In recent years, the development of E-commerce in our country has advanced by leaps and bounds. The development of information network technology and E-commerce has brought new opportunities for poverty alleviation and development work. The so-called E-commerce poverty alleviation is an information-based poverty alleviation model that uses E-commerce as a means to spur online entrepreneurship and online consumption, and promote sales of specialty products in poor regions. The introduction of the E-commerce business model into poverty-stricken areas will help local farmers expand the scope of sales of agricultural and sideline products, reduce operating and circulation costs, effectively increase farmers' income, and help optimize the structure of the agricultural industry. The use of E-commerce to alleviate poverty is an important step to poverty alleviation and poverty alleviation.

In 2013, Premier Li Keqiang also proposed an innovative poverty alleviation model in 2014 to help poverty alleviation. In order to help poor people in remote mountainous areas to embark on an affluent road as soon as possible and achieve the goal of building a comprehensively well-off society as soon as possible, many experts have provided valuable opinions based on their own investigations and researches to provide their own ideas for precision poverty alleviation. $\mathrm{Hu}$ (2016) through his field survey and analysis in the Qinba Mountains, he proposed to improve the infrastructure construction of communication networks, build a rural information platform and seamlessly integrate with the industrial system, use E-commerce platform to open up the rural market, and use new types of communication. The media promotes brand promotion and product marketing of local agricultural products, and tourism agriculture coordinates economic development to achieve the goal of accurate poverty alleviation. Yang (2016) believes that the current technical characteristics of agricultural development and logistics limit the advantages of E-commerce in helping the poor, but government support and the follow-up of E-commerce companies have given us new opportunities for development. He proposed that more government support be needed. Launched innovative brands and promoted the integrated development of Internet Poverty Alleviation+Financial+Tourism to drive regional economic development. 
E-commerce can not only increase income, reduce expenditures, raise living standards, but also increase its own level of self-development, which is conducive to real poverty alleviation. Based on the above analysis, many experts are aware of the enormous potential of E-commerce in helping the poor in the context of the Internet and the completeness of development.

\section{The Significance of Developing Rural E-commerce to Poverty Alleviation}

The rural E-commerce poverty alleviation in ethnic areas refers to the government-led, social sectors, enterprises, farmers, or individual farmers as the main participants, relying on modern Internet technologies, through B2B, B2C, C2C, and other E-commerce platforms, for rural people in ethnic areas. Provide agricultural and sideline products prices and circulation information services, help them purchase cheap and high-quality production materials, and sell on-line local agricultural and sideline products featuring ethnic minorities, in order to reduce transaction costs, increase farmers income, drive prosperity of the surrounding people's production, and promote the development of related industries in ethnic regions. A new type of accurate poverty alleviation model improves the effectiveness of poverty alleviation. This Internet+Agriculture+Poverty Alleviation model was promoted in ethnic regions, which promoted the transformation of traditional agricultural production and management methods from decentralized to scaled, intensified, accurate, and intelligent, creating an excellent opportunity for ethnic regions to completely escape poverty. .

E-commerce in rural areas can promote the formation of characteristic industrial chains in ethnic regions, help the transformation and upgrading of traditional industries, and realize the refinement of poverty governance. The economy in the ethnic areas mainly depends on resource-based industries, and even characteristic industries are based on natural endowments. The new normal economy has forced the transformation and upgrading of industries in ethnic regions. In a short period of time, the reduction of staff, diversions, and waiting posts in the process of eliminating excess capacity and eliminating backward production capacity will also cause economic difficulties for some minority families. E-commerce in rural areas can promote the transformation of ethnic regions from one-way blood transfusions to poverty alleviation and endeavors to improve endogenously driven hematopoietic poverty alleviation and realize the precision of poverty treatment methods. From the perspective of poverty alleviation methods in the current ethnic regions, the main methods are infrastructure improvement, industrial development, education investment, ecological compensation, and social security. However, it is not difficult to see that these measures are obviously insufficient in terms of market functions, and E-commerce poverty alleviation emphasizes market-oriented, equal-trade as a means, and performance-based targeting to help remotely-occluded ethnic villages open the door to the ethnic minority communities.

\section{The Predicament of Rural E-commerce Provisions}

E-commerce Distribution Last-mile Problem. In China's ethnic regions, county and township levels have basically established a logistics distribution platform, but the logistics express delivery network and service system to the villages have not yet been completed, and it is difficult for rural households with poor households to step out of the mountains to the market, and the final of logistics distribution. The problem of one kilometer directly restricts the development of poverty alleviation by rural E-commerce in ethnic regions. During the Twelfth Five-Year Plan period, governments at all levels have increased their input in infrastructure construction and have basically achieved village and village communication in ethnic areas. However, the existing Tongcun road conditions are relatively poor, and landslides, mudslides and other disasters frequently occur, seriously affecting local exchanges and trade with the outside world. Rural areas in ethnic areas are mostly mountainous villages. Once a flash flood erupts, the Tongcun road is washed away, and the relevant departments are difficult to repair in time.

The Shortage of E-commerce Professionals. The development of science and education in ethnic areas is lagging behind, and the education level of poor farmers is relatively low. They are unfamiliar with and unfamiliar with the operating procedures of the Internet and E-commerce related software. 
There may be varying degrees of difficulty in online shopping and sales. E-commerce service stations have almost no technical staff to provide specialized guidance. With the intensified migration of ethnic minorities, the hollowing out of rural areas in ethnic areas is prominent. Young laborers who understand computers and access the Internet go out to work, and the human resources for rural E-commerce development are scarce. Under the existing conditions, young people working in cities can be sent home via online shopping. However, they are far from being able to hydrolyze their thirst, but they cannot replace their leftovers to sell agricultural products on the Internet to increase their income. The poverty alleviation task in ethnic areas is arduous. The township and township officials lack full-time personnel engaged in E-commerce poverty alleviation. The rural E-commerce business mainly depends on the few rural Taobao partners to drive the surrounding farmers. Taobao partners in rural areas help villagers provide online shopping service and sales, and livelihood services. Their income is based on a certain percentage of the amount of purchasing agency sales orders. E-commerce Products Lacking Industry Supports and Brand Effect. There are many types of agricultural products in ethnic areas of China, and the quality of these products is excellent. However, the rural economy has a weak foundation. Many localities still rely on traditional small-scale farming and decentralized management of manual workshops. There is no modern scale industry and a complete industrial chain. E-commerce in rural areas is obviously weak. For example, ecological fruits and vegetables, poultry eggs, and tea and other agricultural and sideline products in ethnic areas are favored by the market. However, because of the lack of closer and effective cooperation and interest linkage between processing enterprises and poor farmers, the production and distribution model based on individual units is difficult to adapt to the rapid growth of electricity suppliers. The development needs, online shop operators cannot keep up with growing customer demand and fall into the plight of stock-out or customs clearance, resulting in farmers cannot continue to increase income, poverty reduction effect is not good.

Insufficient Guidance of E-commerce Pro-poor Policies. The essence of poverty alleviation work is a highly publicized government function and social responsibility. At present, poverty alleviation by rural E-commerce in ethnic regions is mainly based on a market-oriented mode of operation, that is, E-commerce enterprises set up service stations to the countryside to promote the participation of ethnic minority people in E-commerce transactions so that poor rural households, E-commerce and production-oriented enterprises can benefit from it. However, in this model, the E-commerce companies' pursuit of maximization of interest and public value objectives of accurate poverty alleviation are likely to conflict. For example, the location of rural Taobao is usually considered from the perspective of the cost of E-commerce operators, and tends to be in convenient towns and villages. With the rapid economic development and high level of farmers' consumption, the existing rural Taobao is mostly set up in villages and towns that are far from the poor farmers.

\section{Countermeasures for the Sustainable Development of Rural E-commerce Poverty Alleviation}

\section{Building Rural E-commerce Logistics and Public Service Systems.}

In the development-oriented poverty reduction policy system, the necessity and primacy of improving natural conditions cannot be ignored. From the point of view of the long-term poverty households of ethnic minorities, the current cross-district road traffic between counties, townships, and even provinces does not have a positive effect on their income increase and poverty alleviation. Governments at all levels in ethnic areas should focus on the construction of logistics hub stations, coordinate overall arrangements, integrate resources, and jointly develop, and strengthen the organic docking of transportation facilities, agriculture, trade, supply, marketing, and postal logistics facilities and rural E-commerce poverty alleviation. The rural logistics service system at the county, township, and village levels with multiple stations, resource sharing, and perfect functions.

Building a Professional Talent Team for E-commerce Poverty Alleviation. The E-commerce poverty alleviation in rural areas in ethnic regions is the lack of compound talents who are both well-educated and ethnic minority languages and customs. Due to the late start of rural E-commerce in China and the large demand for development in recent years, rural Taobao partners or village cadres only engaged in E-commerce poverty alleviation work part-time, the effect is not satisfactory. Adequate 
E-commerce professionals specializing in poverty alleviation are particularly important for promoting rural E-commerce in poverty-stricken areas in ethnic regions. It is necessary to create a floor-standing E-commerce poverty alleviation professional talent team that can adapt to the characteristics of ethnic and rural villages. On the one hand, the government must formulate preferential policies for the introduction of talents, especially to improve the treatment of talents, provide a good working environment and equipment conditions, and attract more talents to ethnic regions to help rural E-commerce to help the poor. On the other hand, while the government is increasing the number of attracting foreign talents, it must also improve the training mechanism for the local E-commerce poverty alleviation talents in the ethnic regions as soon as possible. The first is to regularly organize poverty-stricken households to learn online typing, online marketing, etc., and support public welfare social organizations to send electricity supplier technology into villages so that ethnic minorities can grasp E-commerce knowledge and operating skills. For poverty-stricken households that have opened online stores, they must take measures to help improve the efficiency of online store operations.

Implement Rural E-commerce Industrial Chain Extension and Brand Upgrading Strategy. First of all, the poverty alleviation of E-commerce in rural areas of ethnic regions must be combined with industrial poverty alleviation, guided by market demand, give full play to the ecological, cultural, and tourism advantages of the ethnic regions, adopt differential assistance, and guide the development of poor households with quick results and prospects. Good, low-risk and characteristic industries will broaden the market for E-commerce and increase the added value of agricultural products. Secondly, it is necessary to innovate the form of the benefit linking of the rural E-commerce industry in the ethnic regions, and encourages poverty-stricken households with many mountainous and forestry resources to achieve land circulation, as well as large-scale and intensive operations through various channels such as cooperatives, agricultural cooperatives, and leasing contracts.

Optimizing the Policy of Rural E-commerce Poverty Alleviation. First, it is necessary to increase financial investment in poverty alleviation by E-commerce in rural areas in ethnic regions, and establish a special fund for E-commerce poverty alleviation for the construction of rural informatization facilities in remote ethnic regions. In the grass-roots poverty alleviation process, we must focus on helping solve the site problems of township and village E-commerce service sites, and coordinate the various departments to provide support for E-commerce and logistics companies in warehousing, business training, market development, and distribution and distribution. Second, we must give a policy tilt to rural E-commerce development in ethnic areas. The county and township governments must accurately identify the ethnic minorities who have the ability to work but are poor due to lack of funds. Small and medium-sized micro-electronics and commercial enterprises that sell products to farmers and purchase them, as well as individual farmers who set up online shops to sell ethnic minority agricultural products, should be given VAT exemptions or deductions. In addition, we must encourage rural logistics enterprises or individuals in ethnic regions to purchase advanced logistics transportation equipment, refrigerated and fresh-keeping equipment, etc. through fiscal subsidies, financial support, etc., and implement the standardized operation of agricultural products and E-commerce logistics in transportation, packaging, processing, storage, etc. In accordance with market requirements, each link encourages the adoption of international or domestic standards and actively develops the transportation of containers and large-scale refrigerated trucks.

\section{Conclusions and Suggestions}

It is necessary to guide logistics enterprises to implement the integration of third-party logistics services in the whole-process whole network, improve the efficiency of E-commerce logistics services, and change the status of slow logistics and backward service in remote ethnic regions. Third, we must extensively implement Internet +Accurate Poverty Alleviation, strengthen mutual promotion and promotion of poverty alleviation policies and models, improve the effectiveness of E-commerce in poverty alleviation, and avoid redundant construction and waste of resources. For example, sales of ethnic tourism products through E-commerce platforms not only increase the income of farmers, but also promote local tourism promotion and attract tourists from all over the world. At the same time, the 
use of tourism cultural resources to expand E-commerce sales channels for agricultural and specialty products can also help poor farmers to increase income, and promote the benign interaction between E-commerce poverty alleviation and tourism poverty alleviation in ethnic regions.

\section{Acknowledgements}

This work was supported by the Modernization and Social Harmonious Development in Ethnic Regions: Research and Innovation Team of Northwest Minzu University (Grant No: 31920180101) and by the Key Laboratory of E-commerce of Ethnic information in Gansu Provincial (Grant No:MDS2017001) and by the Pilot joint program of comprehensive professional reform of International Economics and Trade (Joint Program, USU and NWUN) (Grant No:2017XJZYZHGGSD-01)

\section{References}

[1] Chen Weiwei, The empirical analysis of the construction of the infrastructure construction of university informatization, Journal of Shanghai University of Science and Technology, 2013.

[2] Fan Jiangbo, the influence of E-commerce on international trade and the countermeasures of China. Time Trade, 5 (2008)149-153.

[3]Mou Xiaogang, the application and problems of E-commerce in international trade, science and technology plaza, 2006.

[4] Fang Hao, How to Block Intergenerational Transfer of Poverty in Ethnic Areas, China National Daily, 3 (2017) 20-27.

[5] Kang Chunpeng, E-commerce Poverty Alleviation under the Precision Poverty Alleviation Strategy, Farmers Daily, 3 (2008) 200-211.

[6] Sun Hao, Research on Poverty Reduction in E-commerce and Countermeasures, Agricultural Network Information, 4 (2012)60-71.

[7] Chen Quangong, Research on Long-term Poverty and Developmental Poverty Reduction Policy in Minority Mountainous Areas, Beijing: Science Press, 2014.

[8] Wang Jiawei, The Current Situation and Model Innovation of E-commerce Poverty Alleviation in Depressed Areas during the Thirteenth Five-Year Plan, Agricultural Network Information, 2016. 